University of Nebraska - Lincoln

DigitalCommons@University of Nebraska - Lincoln

1988

\title{
Labeling Anaphes ovijentatus (Hymenoptera: Mymaridae)., an Egg Parasite of Lygus spp. (Hemiptera: Miridae)., with Rubidium
}

Charles G. Jackson

Allen C. Cohen

Charmaine L. Verdugo

Follow this and additional works at: https://digitalcommons.unl.edu/entomologyother

Part of the Entomology Commons

Jackson, Charles G.; Cohen, Allen C.; and Verdugo, Charmaine L., "Labeling Anaphes ovijentatus (Hymenoptera: Mymaridae)., an Egg Parasite of Lygus spp. (Hemiptera: Miridae)., with Rubidium" (1988). Entomology Papers from Other Sources. 109.

https://digitalcommons.unl.edu/entomologyother/109

This Article is brought to you for free and open access by the Entomology Collections, Miscellaneous at DigitalCommons@University of Nebraska - Lincoln. It has been accepted for inclusion in Entomology Papers from Other Sources by an authorized administrator of DigitalCommons@University of Nebraska - Lincoln. 


\title{
Labeling Anaphes ovijentatus (Hymenoptera: Mymaridae), an Egg Parasite of Lygus spp. (Hemiptera: Miridae), with Rubidium
}

\author{
CHARLES G. JACKSON, ALLEN C COHEN, \\ AND CHARMAINE L. VERDUGO ${ }^{1}$ \\ Biological Control of Insects Laboratory, USDA-ARS, \\ Tucson, Arizona 85719
}

\begin{abstract}
Ann. Entomol. Soc. Am. 81(6): 919-922 (1988)
ABSTRACT The eggs of Lygus hesperus (Knight) were labeled with the element rubidium $(\mathrm{Rb})$ by rearing the nymphs and maintaining the adults on diet with 100,500 , or $1,000 \mathrm{ppm}$ rubidium chloride ( $\mathrm{RbCl}$ ). Anaphes ovijentatus (Crosby and Leonard), a parasite of Lygus spp. eggs, was marked with $\mathrm{Rb}$ concentrations above laboratory and field endogenous levels when reared from labeled eggs of Lygus adults fed diets with 500 and 1,000 ppm RbCl. Rb concentrations remained sufficiently high to distinguish labeled parasites from those collected in alfalfa fields for $4 \mathrm{~d}$. The parasites that developed in eggs of $L$. hesperus reared on diet with $1,000 \mathrm{ppm} \mathrm{RbCl}$ tended to be shorter-lived and to produce fewer progeny than those from eggs of Lygus fed diets with lower concentrations, but only differences in longevity of males were statistically significant.
\end{abstract}

KEY WORDS Insecta, physiological ecology, biology, trace element

Anaphes ovijentatus (Crosby and Leonard) is a minute parasitic wasp, $0.5 \mathrm{~mm}$ in length, that develops in eggs of Lygus spp. and other mirids (Stoner \& Surber 1969, Jackson \& Graham 1983). It is a significant parasite of Lygus spp. on a number of host plants in the southwestern desert of the United States (Graham et al. 1986) and on alfalfa in Indiana (Sillings \& Broersma 1974). A labeling technique would be useful to study movement and dispersal of the wasp and to distinguish released parasites from others indigenous to the area.

Any labeling technique must affect the biology and behavior of the insects, and the environment, minimally. Based on available literature and on preliminary tests, we selected for trial the element rubidium $(\mathrm{Rb})$ as an internal physiological marker.

Since Berry et al. (1972) proposed this technique, several workers have labeled phytophagous insects by treating their host plants with a solution of rubidium chloride (RbCl) (Frazer \& Raworth 1974; Stimmann 1974; Shepard \& Waddill 1976; Graham et al. 1978a,b; van Steenwyk et al. 1978b; Alverson et al. 1980; Wolfenbarger et al. 1982; Fleischer et al. 1986). Graham et al. (1978a) demonstrated the movement of $\mathrm{Rb}$ through the food chain from plants to several species of predaceous insects. Payne \& Wood (1984) successfully labeled a phytophagous larva and its ichneumonid parasite by injecting $\mathrm{RbCl}$ into the trunks of pecan trees. Insects also

\footnotetext{
Mention of a trademark or proprietary product does not constitute endorsement by the USDA-ARS for its use over any other product.

${ }^{1}$ Aridland Watershed Management Research Unit, USDA-ARS, 2000 East Allen Road, Tucson, Ariz. 85719.
}

have been labeled by adding $\mathrm{RbCl}$ to artificial diets. Thus, adults of Lepidoptera (Stimmann et al. 1973, Graham \& Wolfenbarger 1977, van Steenwyk et al. 1978a) and of Diptera (McLean et al. 1979, Burns et al. 1983) have been successfully labeled with little effect on their biology when moderate levels of $\mathrm{RbCl}$ were used. In addition, the braconid parasite of Heliothis spp. larvae, Microplitis croceipes (Cresson), was labeled by the addition of $\mathrm{RbCl}$ and three other elements to the artificial diet of its host (K. R. Hopper, personal communication).

\section{Materials and Methods}

Lygus hesperus (Knight) were reared from hatch through the nymphal stages, then maintained as adults on artificial diet (Debolt 1982) to which had been added $0,100,500,1,000$, or $5,000 \mathrm{ppm} \mathrm{RbCl}$. The $\mathrm{RbCl}$ was dissolved in water and added to the diets; then the diets were packaged as described by Patana \& Debolt (1985). Labeled L. hesperus females deposited eggs in packets like those used for diet but filled with Gelcarin (Marine Colloids, Springfield, N.J.). These eggs were exposed to the parasites and held for development and emergence of the parasite wasps. Analyses were done on individually labeled and unlabeled (control) L. hesperus eggs and newly emerged parasite wasps. Additionally, wasps from eggs of Lygus reared on diet with $500 \mathrm{ppm} \mathrm{RbCl}$ were held in cages and provided with water and honey. Each day for $6 \mathrm{~d}, 10$ wasps were analyzed to determine how long the labeled wasps could be distinguished from the control wasps. 
Table 1. Rubidium content of $A$. ovijentatus from eggs of $L$. hesperus reared on diet with different levels of rubidium chloride

\begin{tabular}{ccc}
\hline RbCl $(\mathrm{ppm})$ in diet & $n^{a}$ & $\begin{array}{c}\text { Avg }(\mathrm{SE}) \mathrm{Rb} \\
(\mathbf{n g}) \text { per wasp }\end{array}$ \\
\hline 100 & 11 & $0.33(0.04) \mathrm{a}$ \\
500 & 12 & $1.88(0.27) \mathrm{b}$ \\
1,000 & 12 & $4.17(0.29) \mathrm{c}$ \\
Control & 10 & $0.34(0.07) \mathrm{a}$ \\
\hline
\end{tabular}

Means followed by the same letter are not significantly different ( $P=0.05$; Duncan's [1955] multiple range test).

${ }^{a}$ The number of individuals that were analyzed; three subsamples were analyzed from each wasp.

Individual wasps were placed in a freezer $\left(-10^{\circ} \mathrm{C}\right)$ within a few hours after emergence, held until all treatments were ready for analysis, then ashed in a muffle furnace at $650^{\circ} \mathrm{C}$ for $1 \mathrm{~h}$. The ash was dissolved in $100 \mu$ l of 0.5 or $1.0 \%$ solution of nitric acid in distilled, deionized water. Fresh $(<24 \mathrm{~h}$ old $) L$. hesperus eggs were digested in 1.0 $\mu \mathrm{l}$ of concentrated nitric acid at $60^{\circ} \mathrm{C}$ for $2 \mathrm{~h}$ in Reactitherm vials (SUPELCO, Bellefonte, $\mathrm{Pa}$.), then diluted to $0.5 \%$ nitric acid with $199 \mu$ l of deionized water. Three aliquots of $20 \mu \mathrm{l}$ each were analyzed for each specimen; thus each aliquot was $20 \%$ of the total sample for the wasps and $10 \%$ of the total for the L. hesperus eggs.

Rubidium was measured with a Perkin-Elmer (Perkin-Elmer Corporation, Norwalk, Conn.) model 5000 atomic absorption spectrophotometer with an HGA (Perkin-Elmer) graphite furnace assembly and programmer and a model AS-1 automatic sampler. An electrodeless discharge (EDL) lamp with a wavelength of $780.0 \mathrm{~nm}$ was used. Program parameters were $130^{\circ} \mathrm{C}$ for $20 \mathrm{~s}$ for drying, $700^{\circ} \mathrm{C}$ for $20 \mathrm{~s}$ for charring, and $2,300^{\circ} \mathrm{C}$ for $5 \mathrm{~s}$ for atomization. Standards of $0,0.2,0.4$, and $1.0 \mathrm{ng}$ of $\mathrm{Rb}$ in $20 \mu \mathrm{l} 0.5 \%$ nitric acid were used according to the expected range of the samples. Standards were run with each set of samples and used to calculate regression equations to determine the actual quantities of $\mathrm{Rb}$ in each sample. Differences in levels of $\mathrm{Rb}$ in the wasps were tested for significance by analysis of variance (ANOVA) and where appropriate by Duncan's multiple range test (DMR) (Duncan 1955).

To determine the effects of the different Lygus diet levels on the parasites, newly emerged adults were sexed and paired, and each pair was put into a separate cage and held at $26^{\circ} \mathrm{C}, 70 \% \mathrm{RH}$ and a 14:10 (L:D) photoperiod. The cages were made from 92.4-ml plastic vials with the bottom replaced with nylon organdy. A small oviposition packet (5 $\mathrm{cm}^{2}$ ) containing 20-100 fresh $L$. hesperus eggs was placed in each cage and changed every $24 \mathrm{~h}$. The larger numbers of eggs per packet were used for the first $4 \mathrm{~d}$, when the parasites deposited most of their eggs (Jackson 1986). The wasps were observed daily and longevities were recorded. After exposure to the parasites, the egg packets were held in 100-ml plastic Petri dishes until emergence of the
Table 2. Fate of rubidium in $A$. ovijentatus adults over a 6-d period ${ }^{a}$

\begin{tabular}{cccc}
\hline Day & $n^{b}$ & $\begin{array}{c}\text { Rb (ng) per } \\
\text { whole wasp }\end{array}$ & $95 \%$ CI \\
\hline 1 & 10 & 3.66 & $1.96-5.35$ \\
2 & 10 & 2.10 & $1.57-2.63$ \\
3 & 10 & 1.94 & $1.45-2.43$ \\
4 & 10 & 2.35 & $1.92-2.77$ \\
5 & 10 & 0.92 & $0.65-1.20$ \\
6 & 10 & 1.10 & $0.41-1.80$ \\
\hline
\end{tabular}

${ }^{a}$ The parasite adults were reared from eggs of $L$. hesperus fed a diet with $500 \mathrm{ppm} \mathrm{RbCl}$.

${ }^{b}$ Three subsamples (each one-fifth of total) were analyzed for each of the 10 wasps.

parasite progeny, which took 12-14 d. Packets were examined under a dissecting microscope and the number of parasitized eggs was determined by counting parasite pupae. This number was used as the count for the total number of progeny. Sex of the emerged parasites was also noted. Three replications of 8-10 pairs were done for each diet level, and differences in longevities and progeny production were tested for significance by ANOVA and DMR.

Voucher specimens of Anaphes ovijentatus have been deposited in the Canadian National Collection, Ottawa.

\section{Results and Discussion}

Lygus Eggs. Few L. hesperus nymphs completed development to adults on the diet with 5,000 ppm RbCl; therefore, this level was not tested. $L$. hesperus fed diets with 100,500 , and 1,000 ppm $\mathrm{RbCl}$ produced eggs which contained significantly different amounts of $\mathrm{Rb}(P<0.01, \mathrm{DMR})$, and eggs from all three levels had significantly greater amounts $(P<0.01)$ than occurred in the control eggs. The amounts in nanograms (and the standard errors) of $\mathrm{Rb}$ per individual egg were $0.25(0.25)$, $4.80(0.36), 17.69(0.68)$, and 24.30 (1.04) for the control and the diet levels of 100,500 , and 1,000 ppm, respectively. The large standard error of the mean for the control was because one egg had a high level (2.50 ng) of $\mathrm{Rb}$, but this level did not exceed the levels in any of the labeled eggs. With this one exception, the amounts of $\mathrm{Rb}$ in the $L$. hesperus eggs were less variable than were the amounts in the parasite adults.

Anaphes ovijentatus Adults. Parasites reared from eggs of $L$. hesperus fed diet with 500 and $1,000 \mathrm{ppm} \mathrm{RbCl}$ contained significantly more $(P<$ $0.01, \mathrm{DMR}) \mathrm{Rb}$ than those from the 0 or $100 \mathrm{ppm}$ levels, which had similar amounts (Table 1). An average dry weight of an individual parasite (combined sexes) of $9.1 \mu \mathrm{g}$ was determined by drying and weighing 26 wasps. The amount of $\mathrm{Rb}$ in the wasps averaged 0.02 and $0.05 \%$ of the total dry weight for those from the 500 and 1,000 ppm diet, respectively. The amounts of $\mathrm{Rb}$ in $L$. hesperus eggs averaged 0.08 and $0.11 \%$ of the total dry weight 
Table 3. Longevity and fecundity of $A$. ovijentatus adults from eggs of $L$. hesperus reared on diets with different levels of rubidium chloride

\begin{tabular}{|c|c|c|c|}
\hline $\begin{array}{l}\text { RbCl level } \\
\text { in diet } \\
(\mathrm{ppm})\end{array}$ & $\underset{\Upsilon^{a}}{\operatorname{Avg}}(\mathrm{SE})$ & $\begin{array}{l}\text { Longevity (d) } \\
a^{b}\end{array}$ & $\begin{array}{l}\text { No. progeny } \\
\text { avg }(\mathrm{SE})^{a}\end{array}$ \\
\hline 0 & $9.7(1.79)$ & $9.7(1.20) \mathrm{a}$ & $72.3(8.87)$ \\
\hline 100 & $7.7(1.15)$ & $7.6(2.20) \mathrm{ab}$ & $68.0(8.70)$ \\
\hline 500 & $9.8(0.71)$ & $8.0(0.57) \mathrm{a}$ & $75.0(4.51)$ \\
\hline 1,000 & $5.6(1.49)$ & $3.9(0.38) \mathrm{b}$ & $54.9(5.32)$ \\
\hline
\end{tabular}

${ }^{a}$ There were no significant differences between $\mathrm{RbCl}$ levels for female longevity or number of progeny $(P>0.05$, ANOVA).

${ }^{b}$ Means followed by the same letter are not significantly different $(P=0.05$; Duncan's [1955] multiple range test).

$(\bar{x}=22.1 \mu \mathrm{g}, n=8)$ for the same respective diet levels.

Elimination of Rb. Parasites reared from eggs of $L$. hesperus fed $500 \mathrm{ppm} \mathrm{RbCl}$ lost $40-45 \%$ of the $\mathrm{Rb}$ by the second day after emergence but held this level through day 4. Levels dropped again for the fifth and sixth days, so that only $25-30 \%$ of the original amount of $\mathrm{Rb}$ remained (Table 2). Despite the drop in $\mathrm{Rb}$, the levels in labeled wasps were consistently detectable $(P<0.01)$ from the background levels in laboratory controls $(0.34 \pm 0.07)$ for $4 \mathrm{~d}$. Some levels were detectable on days 5 and 6 , but there was an overlap in $\mathrm{Rb}$ quantities with some control wasps.

Anaphes ovijentatus were collected in alfalfa fields at Glover Ranch, located near Marana, Pima County, Ariz., and analyzed to determine the endogenous $\mathrm{Rb}$ levels. Rubidium levels in seven groups of wasps (71 total) averaged $0.69 \mathrm{ng} \mathrm{Rb}( \pm 0.08)$. The $95 \%$ confidence interval for the field-collected wasps $(0.63-0.74 ; \mathrm{df}=6 ; t=2.447)$ overlapped with those from days 5 and 6 , but not with days 1 to 4 (Table 2). Using the criteria of the average endogenous concentration plus three standard deviations ( $\bar{x}+3 \mathrm{SD}$ ) (Stimmann 1974), a wasp would be considered labeled if it exceeded $0.87 \mathrm{ng} \mathrm{Rb}$. Approximately $50 \%$ of the wasps from days 5 and 6 contained amounts of $\mathrm{Rb}$ below this level.

Longevity and Progeny Production. The longevities of labeled and control wasps were highly variable (Table 3 ). Although wasps from eggs of $L$. hesperus fed on 1,000 ppm diet tended to be shorter-lived than those from controls or from the other treatments, the differences were not significant for females $(P>0.05)$. However, control males, and those from eggs of $L$. hesperus fed $500 \mathrm{ppm}$ diet, lived significantly longer $(P<0.05, \mathrm{DMR})$ than those from the $1,000 \mathrm{ppm}$ diet.

There were no overall significant differences in the number of progeny among the various treatments $(P>0.05 ; \mathrm{df}=3,8 ; F=1.5583)$ (Table 3$)$. However, the wasps from eggs of $L$. hesperus reared on diet with $1,000 \mathrm{ppm} \mathrm{RbCl}$ generally produced fewer progeny than those wasps from the control or other treatments. Comparisons of the data from each of the treatments with the data from the control wasps also showed no significant differences.
As expected, fecundity was extremely variable among individuals and among the replications. A greater proportion (61\%) of the total oviposition occurred on the first day for those wasps from eggs of $L$. hesperus reared on diet with $1,000 \mathrm{ppm} \mathrm{Rb}$ than for wasps from the other treatments (39-48\%). Otherwise, the ovipositional patterns were similar. The sex ratios of the progeny of wasps from the controls and from all treatments were similar. Sex ratios varied from 1.0:1.5 to 1.0:1.9 (males/females).

Using the element rubidium to label the minute parasitic wasps appears to be a workable method to study field movement and dispersal. The procedure of adding the rubidium salt, $\mathrm{RbCl}$, to the host's diet is simple and, at the lower concentrations, has little effect on the parasites' longevity or progeny production. A concentration of $500 \mathrm{ppm}$ labeled the wasps sufficiently well for $4 \mathrm{~d}$ to make them distinguishable from field-collected specimens.

\section{References Cited}

Alverson, D. R., J. N. All \& P. B. Bush. 1980. Rubidium as a marker and simulated inoculum for the black-faced leafhopper, Graminella nigrifrons, the primary vector of maize chlorotic dwarf virus of corn. Environ. Entomol. 9: 29-31.

Berry, W. L., M. W. Stimmann \& W. W. Wolf. 1972. Marking of native phytophagous insects with rubidium: a proposed technique. Ann. Entomol. Soc. Am. 65: 236-238.

Burns, D. W., M. P. Murphy, K. L. Jones, M. L. Parsons, P. Farnsworth, E. T. Ozaki \& R. T. Staten. 1983. Evaluation of internal elemental markers for Mediterranean fruit fly (Diptera: Tephritidae) reared on tagged artificial diets. J. Econ. Entomol. 76: 13971400 .

Debolt, J. W. 1982. Meridic diet for rearing successive generations of $L$. hesperus. Ann. Entomol. Soc. Am. 75: 119-122.

Duncan, D. B. 1955. Multiple range and multiple $F$ tests. Biometrics 11: 1-42.

Fleischer, S. J., M. J. Gaylor, N. V. Hue \& L. C. Graham. 1986. Uptake and elimination of rubidium, a physiological marker, in adult Lygus lineolaris (Hemiptera: Miridae). Ann. Entomol. Soc. Am. 79: 19-25.

Frazer, B. D. \& D. A. Raworth. 1974. Marking aphids with rubidium. Can. J. Zool. 52: 1135-1136.

Graham, H. M. \& D. A. Wolfenbarger. 1977. Tobacco budworm: labeling with rubidium in the laboratory. J. Econ. Entomol. 70: 800-802.

Graham, H. M., D. A. Wolfenbarger \& J. R. Nosky. 1978a. Labeling plants and their insect fauna with rubidium. Environ. Entomol. 7: 379-383.

Graham, H. M., D. A. Wolfenbarger, J. R. Nosky, N. S. Hernandez, Jr., J. R. Llanes \& J. A. Tamayo. $1978 \mathrm{~b}$. Use of rubidium to label corn earworm and fall armyworm for dispersal studies. Environ. Entomol. 7: 435-438.

Graham, H. M., C. G. Jackson \& J. W. Debolt. 1986. Lygus spp. (Hemiptera: Miridae) and their parasites in agricultural areas of southern Arizona. Environ. Entomol. 15: 132-142. 
Jackson, C. G. 1986. Effects of cold storage of adult Anaphes ovijentatus on survival, longevity, and oviposition. Southwest. Entomol. 11: 149-153.

Jackson, C. G. \& H. M. Graham. 1983. Parasitism of four species of Lygus (Hemiptera: Miridae) by Anaphes ovijentatus (Hymenoptera: Mymaridae) and an evaluation of other possible hosts. Ann. Entomol. Soc. Am. 76: 772-775.

McLean, J. A., I. G. Stump, J. M. D'Auria \& J. Holman. 1979. Monitoring trace elements in diets and life stages of the onion maggot, Hylemya antiqua (Diptera: Anthomyiidae), with X-ray energy spectrometry. Can. Entomol. 111: 1293-1298.

Patana, R. \& J. W. Debolt. 1985. Rearing Lygus hesperus in the laboratory. USDA-ARS, ARS-45.

Payne, J. A. \& B. W. Wood. 1984. Rubidium as a marking agent for the hickory shuckworm Cydia caryana (Lepidoptera: Tortricidae). Environ. Entomol. 13: 1519-1521.

Shepard, M. \& V. H. Waddill. 1976. Rubidium as a marker for Mexican bean beetles, Epilachna varivestis. Can. Entomol. 108: 337-339.

Sillings, J. O. \& D. B. Broersma. 1974. The parasites of the tarnished plant bug Lygus lineolaris in Indiana. Proc. No. Cent. Branch Entomol. Soc. Am. 29: 120-125.
Stimmann, M. W. 1974. Marking insects with rubidium: imported cabbageworm marked in the field. Environ. Entomol. 3: 327-328.

Stimmann, M. W., W. W. Wolf \& W. L. Berry. 1973. Cabbage loopers: biological effects of rubidium in the larval diet. J. Econ. Entomol. 66: 324-326

Stoner, A. \& D. E. Surber. 1969. Notes on the biology and rearing of Anaphes ovijentatus, a new parasite of Lygus hesperus in Arizona. J. Econ. Entomol. 62: 501-502.

Van Steenwyk, R. A., G. R. Ballmer, A. L. Page \& H. T. Reynolds. 1978a. Marking pink bollworm with rubidium. Ann. Entomol. Soc. Am. 71: 81-84.

Van Steenwyk, R. A., G. R. Ballmer, A. L. Page, T. J. Ganje \& H. T. Reynolds. 1978b. Dispersal of rubidium-marked pink bollworm. Environ. Entomol. 7: 608-613.

Wolfenbarger, D. A., H. M. Graham, J. B. Nosky \& O. H. Lindig. 1982. Boll weevil (Coleoptera: Curculionidae): marking with rubidium chloride sprays on cotton and dispersal from cotton. J. Econ. Entomol. 75: 1038-1041.

Received for publication 2 November 1987; accepted 11 July 1988 